\title{
Stable phase formation in a 85.67 wt. \% Cu- 9.9 wt. \% Al- 4.43 wt. \% Ni shape memory alloy
}

\author{
S.M. Chentouf ${ }^{\mathrm{a}}$, M. Bouabdallah ${ }^{2}$, H. Cheniti $^{1}$, M. Keddam ${ }^{1}$ \\ ${ }^{1}$ Département de Science des Matériaux, Faculté de Génie Mécanique et de Génie des Procédés, Université des \\ Sciences et de la Technologie Houari Boumedienne, B.P.32, 16111 El-Alia Bab-Ezzouar, Alger, Algérie. \\ ${ }^{2}$ Laboratoire de Génie Sismique et Dynamique des Structures, Ecole Nationale Polytechnique d'Alger, B.P. 182, \\ 10 Avenue Hassen Badi, 16200, El-Harrach, Alger, Algérie.
}

\begin{abstract}
Cu- 9.9 wt.\% Al- 4.43 wt.\% Ni shape memory alloy has been studied. Polycrystalline specimens have been quenched, into water, after heat treatment at high temperature and followed by two successive runs from room temperature to $923 \mathrm{~K}$ and inversely. The microstructural and thermodynamic studies presented in this work have been performed using DSC (Differential Scanning Calorimetry), X-ray diffraction analysis at a variable temperature and TEM (Transmission Electron Microscopy) analysis. Stable phase precipitation of AlNi type was observed to appear in this alloy.

Keywords: Martensitic transformation; Shape memory alloys; AlNi precipitation.
\end{abstract}

\section{Introduction}

Shape memory alloys constitute an important group of smart materials. Among these materials the $\mathrm{Cu}-\mathrm{Al}-\mathrm{Ni}$ system offers the best potential for high temperatures applications (near $493 \mathrm{~K}$ ) [1,2], it presents an advantage over $\mathrm{Cu}-\mathrm{Zn}-\mathrm{Al}$ and $\mathrm{Ti}-\mathrm{Ni}$ alloys where their maximum working temperature is around of $373 \mathrm{~K} \mathrm{[3].} \mathrm{Cu}-\mathrm{Al}-\mathrm{Ni}$ system is known to have at high temperature a V-shaped single phase field which contains the stable disordered cubic $\beta$ phase. The martensitic transformation of $\beta$ phase is responsible for the shape memory properties exhibited by $\mathrm{Cu}-\mathrm{Al}$ alloys. During a decrease of the temperature at quenching, the disordered $\beta$ stable phase undergoes two successive ordering processes [4], and the resulting phase at room temperature has a $\mathrm{L} 2{ }_{1}$ cubic order [5]. Closer to the $\beta$ single field phase, we have the existence of the $\alpha$ and $\gamma_{2}$ phases. The $\gamma_{2}$ phase appears during heating as a primary precipitation previous to the eutectoid reaction $\beta \rightarrow \alpha+\gamma_{2}$ [6], the crystallographic structure of this phase is described as a binary $\mathrm{Cu}_{9} \mathrm{Al}_{4}$ structure in $\mathrm{Cu}-\mathrm{Al}-\mathrm{Ni}$ [7] with a cubic cell parameter equal to $8.7039 \AA$. The $\alpha$ phase is a disordered cubic phase $(\mathrm{a}=3.682 \AA)$ with a space group with very low aluminium and nickel content [8,9]. A Cu-Al-Ni alloy with an eutectoid composition exhibits the same particularities of the binary $\mathrm{Cu}-\mathrm{Al}$ alloy. In fact, a slow cooling from the $\beta$ high temperature phase gives rise to a lamellar eutectoid mixture $\left(\alpha+\gamma_{2}\right)$, at a temperature lower than $840 \mathrm{~K}$.

The purpose of the present work was to study the influence of high proportion of nickel, on the microstructural and thermodynamical evolutions, during heating- cooling double thermal cycles, from room temperature to $923 \mathrm{~K}$ and inversely.

\section{Experimental procedures}

Polycrystalline samples of $\mathrm{Cu}-\mathrm{Al}-\mathrm{Ni}$ with a nominal composition of $\mathrm{Cu}-9.9$ wt.\% Al- 4.43 wt.\% Ni (Cu- 20.5 at.\% Al- 4.21 at. $\% \mathrm{Ni}$ ) have been used. The samples were annealed at $1123 \mathrm{~K}$ for $15 \mathrm{~min}$ and quenched in a room temperature water to obtain the $\beta$ phase (L2 1 cubic order). DSC measurements were performed on several samples under an argon atmosphere. These heat treatments, consisting of two successively heating-cooling

${ }^{a}$ e-mail: chent_s@yahoo.com

This is an Open Access article distributed under the terms of the Creative Commons Attribution-Noncommercial License (http://creativecommons.org/licenses/by-nc/3.0/), which permits unrestricted use, distribution, and reproduction in any noncommercial medium, provided the original work is properly cited. 
cycles, were done inside the DSC equipment under a rate of $5 \mathrm{~K} / \mathrm{min}$ in the temperatures range (298-1123 K), with a holding time of a few minutes at high temperature. The phases formed were determined based on the electron probe microanalysis (EPMA) compositional measurement, XRD analysis, at variable temperatures, using the $\mathrm{Cu} \mathrm{K} \alpha$ radiation. Finally, a transmission electron microscopy (TEM) study was performed using of a Philips CM20 TEM operating at $200 \mathrm{kV}$. The thin foils were prepared, polished mechanically, and electropolished to electron transparency using a solution of perchloric acid and acetic acid.

\section{Results and discussion}

The quenched structure exhibits a biphase structure formed by the martensitic $\beta^{\prime}$ phase and the $\alpha$ phase (see Fig.1). DSC thermograms Fig.2, show on heating for the first run an exothermic evolution called (A) linked to the precipitation of AlNi phase [11,12] with a calculated energy of $3.71 \mathrm{~J} / \mathrm{g}$. The next transformation, evolution (B) $(7.75 \mathrm{~J} / \mathrm{g})$, corresponds to the reverse transformation of the martensite $\beta^{\prime}$ to an intermediate metastable $\beta$ phase. This latter evolution is followed by the exothermic evolution (C) $(4.09 \mathrm{~J} / \mathrm{g})$, which corresponds to the formation of the equilibrium phases $\left(\alpha+\gamma_{2}\right)$ [13]. At around of $843 \mathrm{~K}$, it appears a new endothermic evolution $(8.85 \mathrm{~J} / \mathrm{g})$, called (D), which is relative to the formation of the higher stable $\beta$ phase via the dissolution of $\gamma_{2}$ phase and a part of $\alpha$ phase. Also for this transformation, it is noticed the disappearance of AlNi phase.

With respect to the cooling, we observe just only an exothermic evolution (E), which corresponds to the decomposition of $\beta$ phase into equilibrium constituents $\left(\alpha+\gamma_{2}\right)$ with energy of $10.5 \mathrm{~J} / \mathrm{g}$ and formation of AlNi phase. For the second run of heating, the thermogram shows only an endothermic evolution $(\alpha+\beta)$, with a narrow domain of the transformation $(14.06 \mathrm{~J} / \mathrm{g})$. As it can be seen, the thermogram of cooling is similar to the first one. In order to confirm the different evolutions, Figs. 3 and 4 provide different X-ray diffraction patterns during heating and cooling respectively. During cooling (at $802 \mathrm{~K}$ ) we can see, for $50 \%$ of transformation, a peak relative to the $\beta$ phase which disappears after. At room temperature, an existence of $\mathrm{Al}_{\mathrm{x}} \mathrm{Ni}_{\mathrm{y}}$ phase, corresponding to AlNi type precipitate is revealed. It diffracts according to (110) plane. On one hand, the compositional analysis by using EPMA indicates the bright and continuous phase is the $\alpha$ phase (Cu- 18.5 at.\% Al- 3 at.\% Ni), while the dark phase is AlNi phase (Cu- 41.8 at\%.Al- 41.42 at.\%.Ni), see Fig.5. On the other hand, the dosage by cartography X (STEM) gives the elemental distribution inside the precipitates. It also confirms the nature of these precipitates.

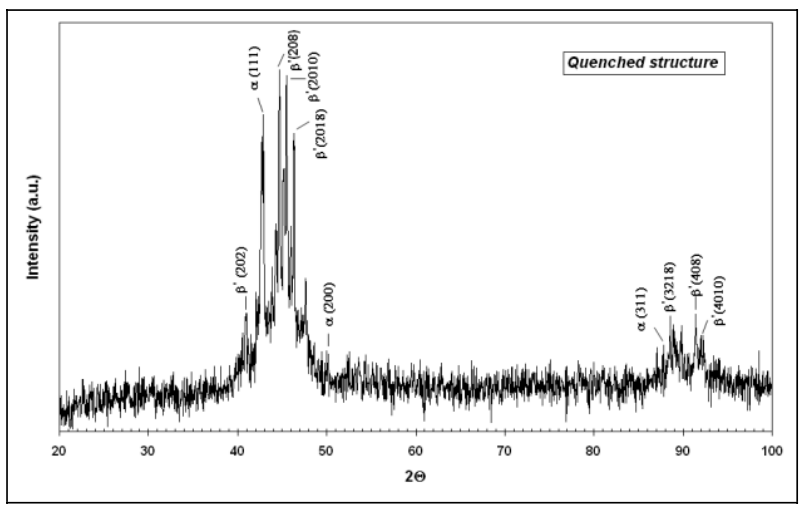

Fig.1. Quenched structure.

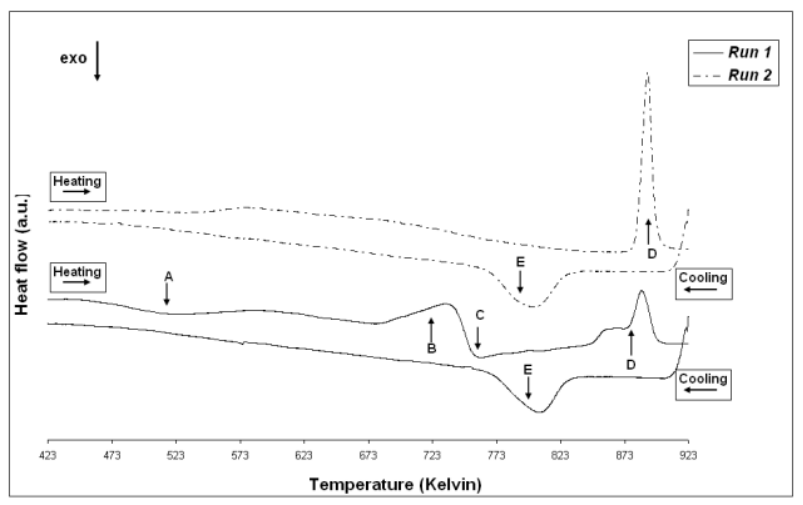

Fig.2. DSC thermograms [10]. 


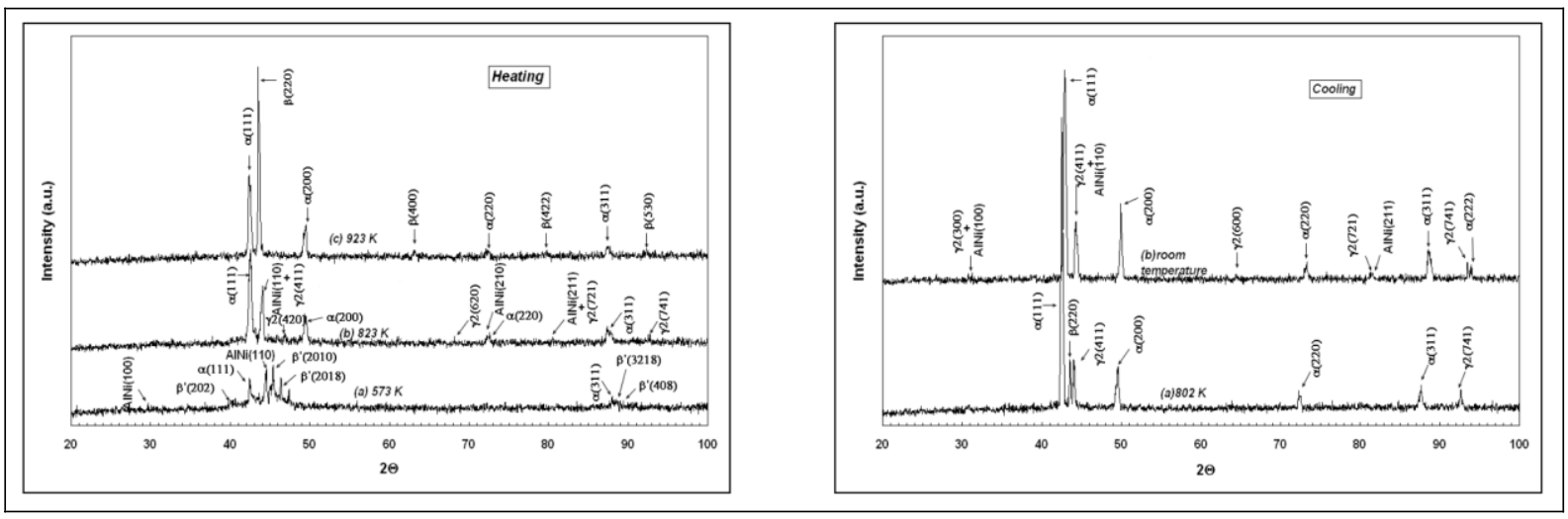

Fig.3. X-ray diffraction patterns of heating and cooling (run 1).

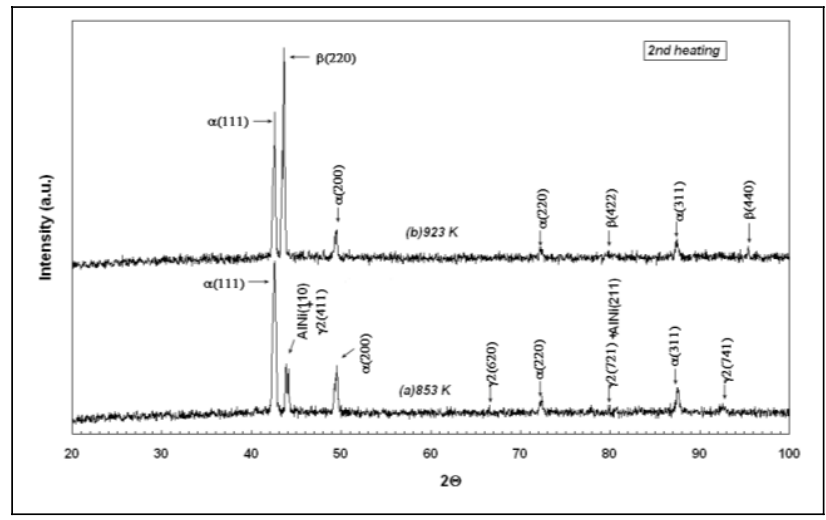

Fig.4. X-ray diffraction patterns of heating (run 2).

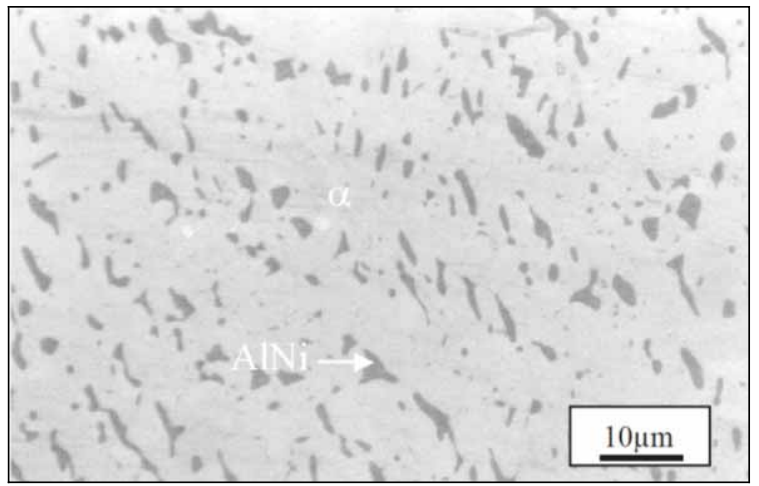

Fig.5. BEI micrograph after the second run. 


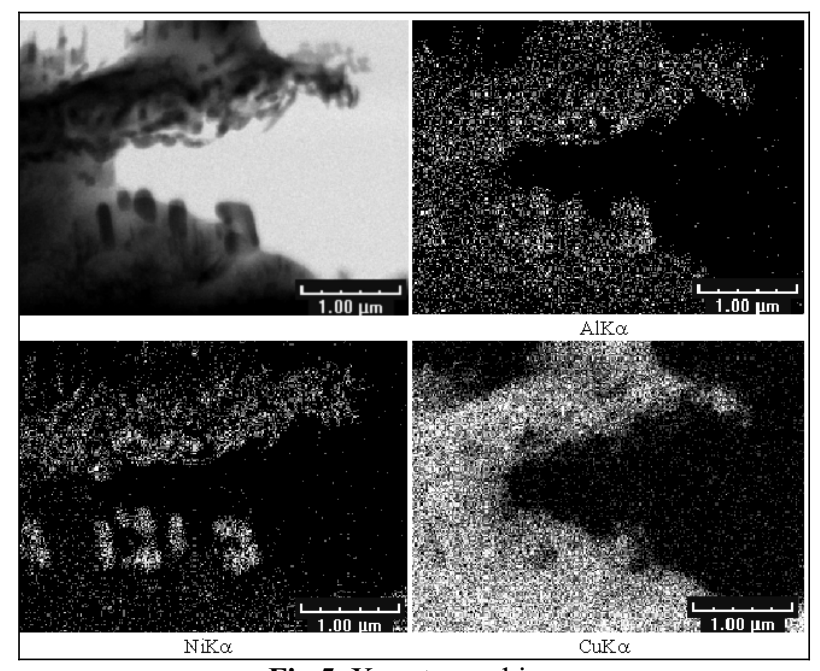

Fig.5. X-cartographies.

\section{Conclusion}

The following concluding points can be drawn from our experimental results as follows:

- Precipitation of a very stable AINi phase, result confirmed by XRD, EPMA and STEM analysis.

- During a second heating, the exothermic evolution called (A) linked to the precipitation of AlNi phase does not appear.

\section{References}

[1] H. Funakubo. Shape Memory Alloys, Precision Machinery and Robotics, vol. 1, Gordon and Breach, New York, (1987).

[2] T.W. Duerig, K.N. Melton, D. Stöcked, C.M. Wayman (Eds.). Engineering Aspects of Shape Memory Alloys, Butterworths-Heinemann, London, (1990).

[3] L.Delaey. in:P.Haasen (Ed), Phase Transformation in Materials, VCH Weinheim, (1991).

[4] V. Recarte, O.A. Lambri, R.B. Pérez-Sáez, M.L. Nó and J. San Juan. Appl Phys Lett. 70, 3513 (1997).

[5] J.I. Pérez-Landazábal, V. Recarte, R.B. Pérez-Sáez, M.L. Nó, J. Campo, and J. San Juan. Appl Phys Lett. 81, 1794 (2002).

[6] V. Recarte, I. Hurtado, J. Herreros , M.L. No', J. San Juan. Scripta Mater, (1996); 34:255.

[7] E.G. Petzow, E. Effenberg. Ternary Alloys, vol. 4. Wienheim:VCH; (1991).

[8] P. Brezina. Inter Metals Rew, (1982); 27:77.

[9] Y.S. Sun, G.W. Lorimer, N. Ridley. Metall Trans, (1990); 21A:575.

[10] S.M. Chentouf, M. Bouabdallah, J-C. Gachon, E. Patoor, A. Sari. J.Alloys Compd. 470 (2009), 507-514.

[11] M. Bouabdallah, G. Cizeron. Eur. Phys. J. AP 1, 163-172 (1998).

[12] V. Recarte, J.I. Pérez-Landazábal, A. Ibarra, M.L. Nó, J. San Juan. Mater. Sci. Eng. A 378 (2004) 238.

[13] J.I. Pérez-Landazábal, V. Recarte and V. Sánchez-Alarcos. J. Phys.: Condens. Matter 17 (2005) 4223-4236. 